\title{
NOTAS PARA A INTERPRETAÇÃO DAS DESIGUALDADES RACIAIS NA EDUCAÇÃO
}

\author{
DANIELLE OLIVEIRA VALVERDE \\ Fundo de Desenvolvimento das Nações Unidas para a Mulher \\ LAURO STOCCO \\ Ministério da Educação
}

\begin{abstract}
Resumo: Este artigo discute os dados educacionais compilados na $3^{a}$ edição do Retrato das desigualdades de gênero e raça, enfatizando a importância da compreensão de como as diferentes situações e os processos sociais vivenciados pelas crianças e pelos jovens brancos e negros no interior do sistema educacional afetam sua permanência, progressão e desempenho escolar. Como principais achados destacam-se a queda da histórica diferença de escolaridade entre brancos e negros de mais de 15 anos, a cristalização da diferença de escolaridade entre crianças brancas e negras de 7 a 14 anos e a menor taxa de crescimento do acesso ao ensino superior das mulheres negras em comparação aos homens negros. Por fim, é apontada a importância da articulação de diferentes ações para a superação das desigualdades raciais na educação.
\end{abstract}

Palavras-chave: desigualdades raciais; preconceito e discriminação; ações afirmativas; políticas públicas.

\section{Introdução}

O presente artigo tem como objetivo discutir os dados educacionais compilados na $3^{a}$ edição do Retrato das desigualdades de gênero e raça à luz da produção mais recente acerca das situações de preconceito e discriminação raciais presentes no sistema educacional brasileiro. ' A primeira seção destaca que a partir de 2002, após várias décadas de estabilidade, inicia-se uma tendência de queda na diferença de escolaridade entre brancos e negros. Nesse mesmo período, entretanto, inicia-se a cristalização de uma

Copyright ã 2009 by Revista Estudos Feministas.

${ }^{1}$ As ideias expressas neste texto não representam a posição do Fundo de Desenvolvimento das Nações Unidas para a Mulher nem do Ministério da Educação. 
diferença de escolaridade entre crianças brancas e negras de 7 a 14 anos, o que aponta para a necessidade de compreensão dos processos que contribuem para a manutenção dessa desigualdade. A segunda seção apresenta os mecanismos pelos quais o preconceito e a discriminação operam no ambiente escolar, processos esses que afetam diretamente a permanência, a progressão e o desempenho escolar das crianças e dos jovens brancos e negros. Por fim, a última seção aborda o ensino superior especificamente, mostrando que, apesar da diminuição da desigualdade de acesso de brancos e negros à universidade nos últimos anos, ainda é pequena a presença de negros/as nas universidades brasileiras, o que corrobora com a relevância da discussão sobre ações que mitiguem esse problema.

\section{Quadro das desigualdades raciais na educação}

Diferentemente do que ocorria até o ano de 2001, a análise dos dados das últimas edições disponíveis da Pesquisa Nacional por Amostra de Domicílios (PNAD) mostra uma diminuição na diferença entre a média de anos de estudo de brancos e negros. ${ }^{2}$ Luciana Jaccoud e Natalie Beghin ${ }^{3}$ e também Ricardo Henriques ${ }^{4}$ apontam que até 2001 , a despeito dos avanços obtidos pelo Brasil em educação na década de 1990, a diferença entre a média de anos de estudo de brancos e negros permaneceu aproximadamente constante, em torno de dois anos. Para Henriques, ${ }^{5}$ o mais impressionante na desigualdade educacional entre brancos e negros é sua estabilidade ao longo do século XX, uma vez que a diferença na escolaridade média entre os adultos brancos e negros nascidos em 1974 é idêntica entre os nascidos em 1929 - mostrando que o padrão de discriminação racial na educação manteve-se estável entre gerações.

Essa situação, entretanto, parece ter encontrado seu ponto de inflexão em 2002. Nesse ano, a diferença entre a média de anos de estudo de brancos e negros foi, pela primeira vez desde que a PNAD passou a coletar o quesito cor/raça, menor que dois anos, ficando em 1,9. Essa queda, que poderia ser interpretada pelos mais céticos como anômala em uma séria história na qual a diferença de escolaridade entre brancos e negros estaria cristalizada em torno de dois anos, acabou se mostrando, nos anos seguintes, como a nova tendência desse indicador (conforme pode ser visto na Tabela 1).

Considerando-se as questões metodológicas centrais ao processo de reprodução das desigualdades sociais e as transformações pelas quais o sistema educacional brasileiro tem passado desde meados dos anos 1990, não gera espanto a verificação desse recuo das desigualdades raciais na educação. As desigualdades sociais, aqui especificamente as raciais, ${ }^{\circ}$ retratadas pelas estatísticas nacionais, são os resultados - digamos, brutos - de variados processos sociais. As desigualdades educacionais entre brancos e negros resultam inegavelmente de processos discriminatórios vivenciados pelos estudantes negros, mas não só disso.

\footnotetext{
${ }^{2}$ Para o Instituto Brasileiro de Geografia e Estatística (IBGE) e outros órgãos oficiais do governo brasileiro, a categoria "negro" é composta de pardos e pretos.

${ }^{3}$ Luciana de Barros JACCOUD e Natalie BEGHIN, 2002.

${ }^{4}$ Ricardo HENRIQUES, 2001.

${ }^{5}$ HENRIQUES, 2001.

"Neste texto são empregados os termos "raça", "inscrição racial" e "variável raça". A diferença entre eles não é meramente semântica, mas sim fruto de suas diferentes origens disciplinares e metodológicas. Todos eles, entretanto, possuem em comum o reconhecimento de que as relações sociais no Brasil possuem um importante componente racial, ou seja, são informadas por ideias e categorias baseadas no conceito (histórica e socialmente construído) de raça. Ver Antônio Sérgio Alfredo GUIMARÃES, 2003 e 2004; e Kabengele MUNANGA, 2004.
} 

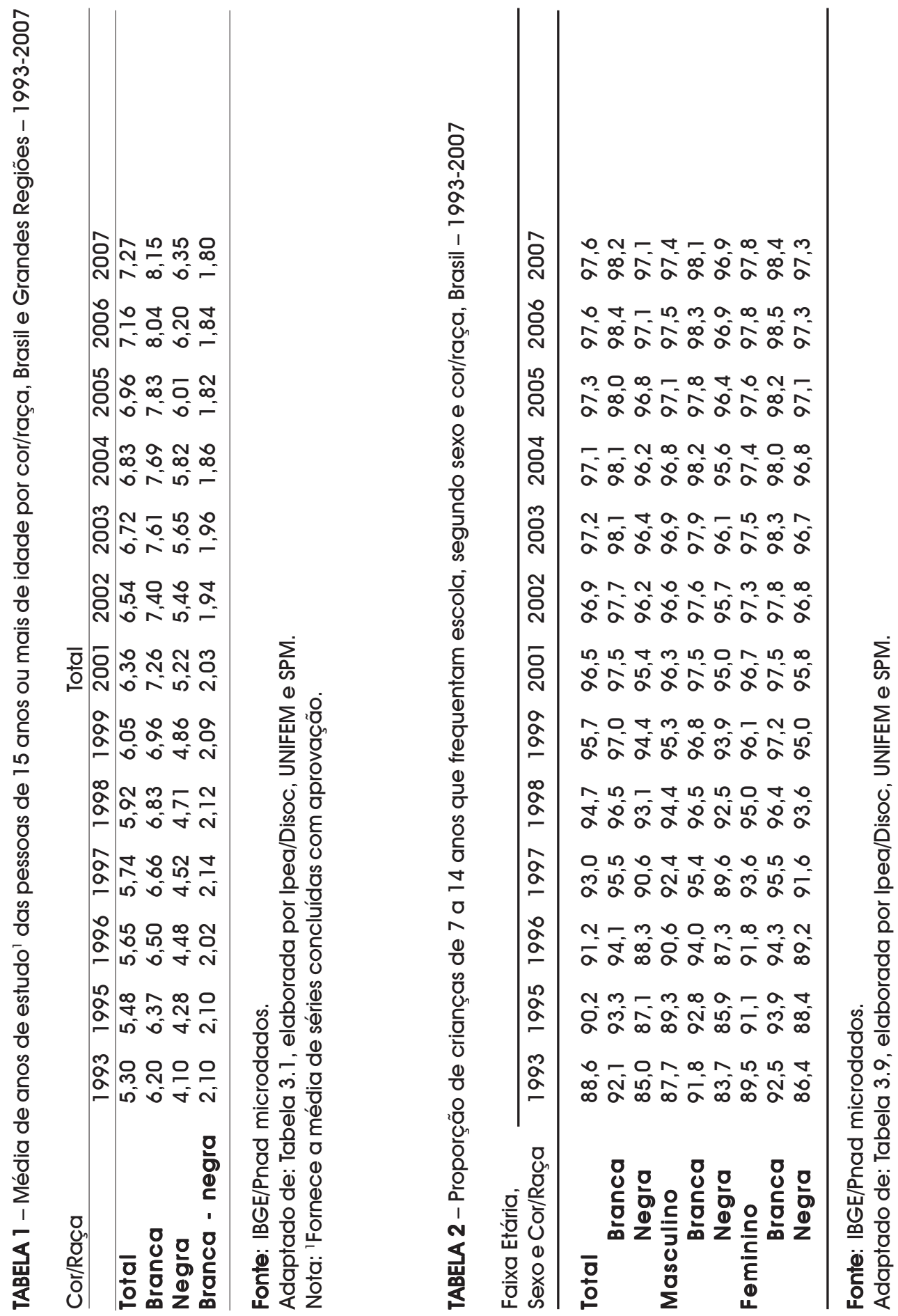
Segundo Carlos Hasenbalg e Nelson do Valle Silva, ${ }^{7}$ além das questões ligadas à inscrição racial dos estudantes, as desigualdades educacionais entre brancos e negros são geradas por diferenças de renda, região de domicílio, estrutura familiar, escolaridade dos pais e estrutura do sistema de ensino. Todavia, normalmente, as análises dos indicadores educacionais prendem-se mais às questões do lado da oferta educacional, principalmente àquelas relacionadas à qualidade do ensino oferecido pelas escolas brasileiras. Sem deixar de reconhecer a importância de todos esses fatores, o que importa aqui é destacar a contribuição específica da inscrição racial - ou dos processos relacionados a ela - na reprodução das desigualdades raciais na educação.

A análise descritiva da média de anos de estudo da população brasileira desagregada por idade apresenta uma pista da existência de um efeito da variável cor/ raça sobre as desigualdades educacionais. A universalização do acesso à educação fundamental promovida na década de 1990 foi indubitavelmente benéfica à população negra. ${ }^{8}$ Conforme pode ser visto na Tabela 2 , a expansão do acesso à educação fundamental foi acompanhada por uma acentuada queda da desigualdade de acesso ao sistema educacional pelas crianças brancas e negras de 7 a 14 anos, caindo de aproximadamente 7 pontos percentuais em 1993 para apenas 1 ponto em 2007.

Essa diminuição das desigualdades raciais na educação pela universalização do acesso ao ensino parece ter, contudo, um "limite racial". Curiosamente, o mesmo período no qual houve o rompimento da barreira dos dois anos de diferença entre a média de anos de estudo de brancos e negros também foi o período no qual parece ter-se iniciado a cristalização de outra diferença, a da média de anos de estudo entre brancos e negros de 7 a 14 anos. Conforme se pode ver na Tabela 3, a diferença entre a média de anos de estudo de brancos e negros de 7 a 14 anos sofreu uma queda vertiginosa entre 1999 e 2001 , de 0,67 para 0,43 ano de estudo. Mas depois disso, a partir de 2002, essa diferença se estagnou em aproximadamente três décimos $(0,3)$ de ano.

Considerando que foi justamente no ensino fundamental - que atende principalmente às crianças de 7 a 14 anos - que o Brasil alcançou seus melhores resultados educacionais no período compreendido entre a década de 1990 e os primeiros anos do século XXI, é no mínimo intrigante a permanência desse resíduo de diferença entre brancos e negros nesse segmento educacional. Não menos intrigante é a constatação de que não há sequer um indicador educacional no qual haja uma inversão de posições, com negros à frente dos brancos. Tendências como essa fizeram Henriques ${ }^{9}-$ ao analisar os dados educacionais da PNAD das edições compreendidas entre 1992 e 1999 - pontificar que as "políticas de acesso universal e progressão continuada desenvolvidas nos últimos anos" obtiveram um êxito parcial, pois a análise separada dos dados educacionais dos jovens brancos e negros mostra que "o desempenho não é homogêneo entre as raças".

Os dados acima indicam que, mesmo sendo altamente benéfica à população negra, a universalização do acesso ao ensino não é suficiente para a superação das desigualdades raciais na educação. A existência desse resíduo de desigualdade entre brancos e negros em um segmento da educação que atingiu há anos números muito próximos da total universalização do acesso aponta para a necessidade da identificação, da compreensão e do reconhecimento dos processos sociais racializados que produzem essas desigualdades educacionais. Dessa maneira, nos últimos anos, há um deslocamento

\footnotetext{
${ }^{7}$ Carlos HASENBALG e Nelson do Valle SILVA, 1999; e SILVA e HASENBALG, 2000 e 2002.

${ }^{8}$ Mesmo que, em um primeiro momento, essa expansão tenha acontecido em detrimento da qualidade do ensino e sem uma rediscussão acerca dos conteúdos abordados em um sistema escolar que foi construído, ao longo de décadas, para atender a um público de classe média, branco e masculino.

${ }^{9}$ HENRIQUES, 2001, p. 28.
} 


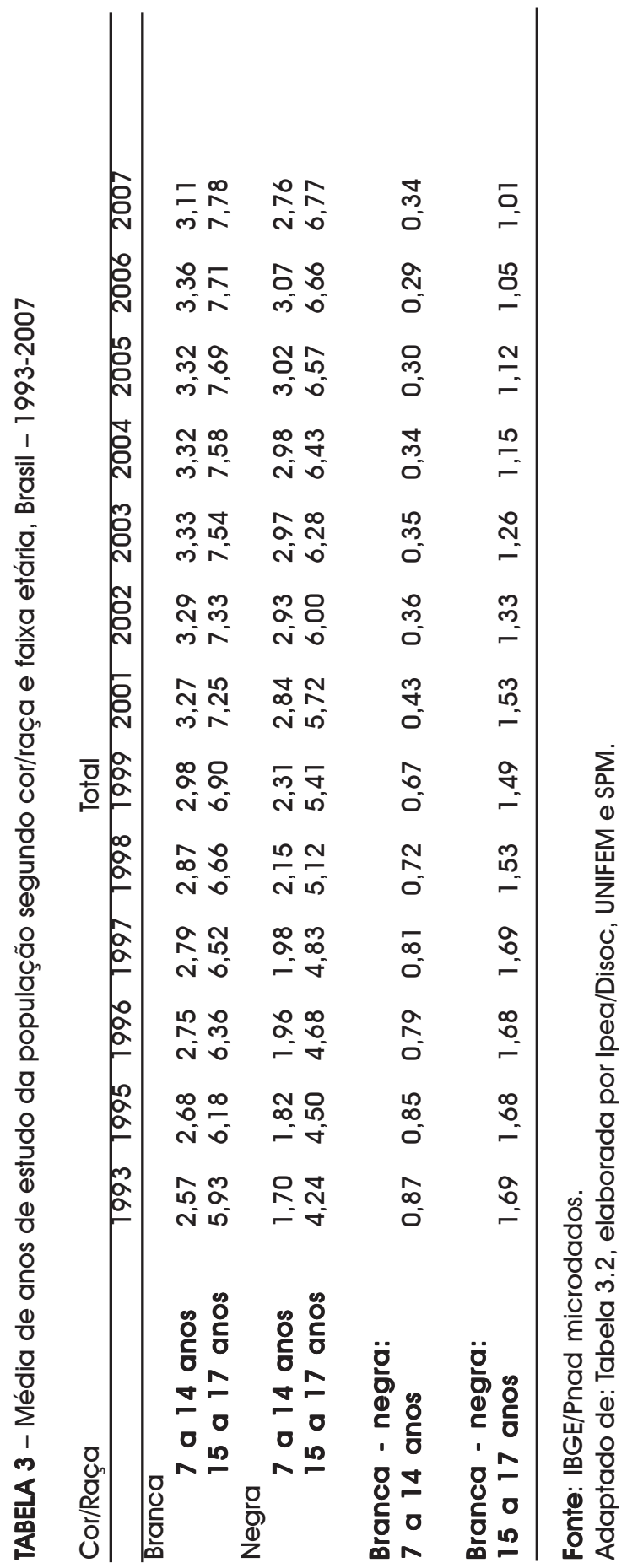


da problemática das desigualdades raciais do acesso à educação para o diagnóstico do interior do sistema educacional, pois as diferentes experiências vivenciadas por crianças e jovens brancos e negros na escola têm efeito direto em sua permanência, progressão e desempenho. ${ }^{10}$

\section{Preconceito e discriminação na escola}

O ambiente escolar, tal como microcosmo da sociedade brasileira, apresenta mecanismos racistas e sexistas que se conformam para a exclusão ou o atraso escolar dos jovens do sistema educacional desde a mais tenra idade. Estudos qualitativos identificam a ocorrência de discriminação e preconceito racial nas relações intracomunidade escolar, tanto entre pares (alunos e alunos) quanto na relação hierárquica entre professores e alunos, e mesmo da direção escolar.

Em estudo realizado com a educação infantil, Eliane Cavalleiro"1 identificou as seguintes situações: a ausência da população negra em cartazes, fotos e informativos fixados no espaço escolar; a omissão de professores diante das situações de discriminação sofridas por crianças negras; ${ }^{12}$ a prática de adjetivação desumanizadora das crianças negras também por parte dos professores; e o estímulo e o tratamento mais afetivo legado à criança branca. Em detrimento dessas práticas, a autora destaca a observação da afetividade e do contato físico identificado entre crianças negras e brancas, demonstrando que a discriminação não é algo intrínseco, mas construída ao longo do processo de socialização.

Além disso, cabe ressaltar a ainda frequente invisibilidade da população negra nos livros didáticos ou a sua presença desumanizada e exotizada - por vezes, associada exclusivamente à escravidão, maximizando as elaborações negativas em torno das crianças e dos jovens identificados com essas imagens. Andréia Souza, ${ }^{13}$ no entanto, aponta para mudanças empreendidas por algumas editoras e autores, que buscam a afirmação de uma imagem positiva das personagens negras, a valorização de elementos culturais herdados das culturas africanas e a valorização das diferenças étnico-raciais.

Ainda assim, há no Brasil uma cultura de negação da existência de práticas racistas no meio escolar que prefere atribuir o fracasso escolar de jovens e crianças negras exclusivamente à desestruturação familiar, à condição socioeconômica ou à necessidade precoce de se inserirem no mercado de trabalho, sem considerar o peso que o pertencimento racial tem sobre suas trajetórias.

As práticas e os mecanismos destacados acima contribuem diretamente para os dados de distorção idade-série, resultados do abandono ou da reprovação de crianças e jovens negros. Embora a diferença entre as taxas de distorção idade-série de brancos e negros no ensino fundamental venha diminuindo, ela ainda é elevada, constituindo-se quase o dobro uma da outra. Conforme se pode observar na tabela a seguir, enquanto as crianças brancas possuíam em 2007 uma taxa de 17,4\%, as crianças negras nessa situação somavam $30,8 \%$, uma diferença de 13,4 pontos percentuais.

\footnotetext{
${ }^{10}$ Mais informações sobre o desempenho desigual de estudantes brancos e negros avaliados pelo Ministério da Educação por meio do Sistema de Avaliação da Educação Básica (SAEB) podem ser vistas em Alicia Maria Catalano de BONAMINO, Francisco Creso Junqueira FRANCO e Fátima ALVES, 2005; e José Francisco SOARES e Maria Teresa Gonzaga ALVES, 2003.

"Eliane dos Santos CAVALLEIRO, 2005.

12 Nilma Lino GOMES (1996) destaca que o silenciamento e o discurso da igualdade são recursos utilizados como estratégia para invisibilizar alunos/as negros/as no ambiente escolar e se furtar à discussão sobre as relações raciais no Brasil.

${ }^{13}$ Andréia Lisboa de SOUZA, 2005.
} 


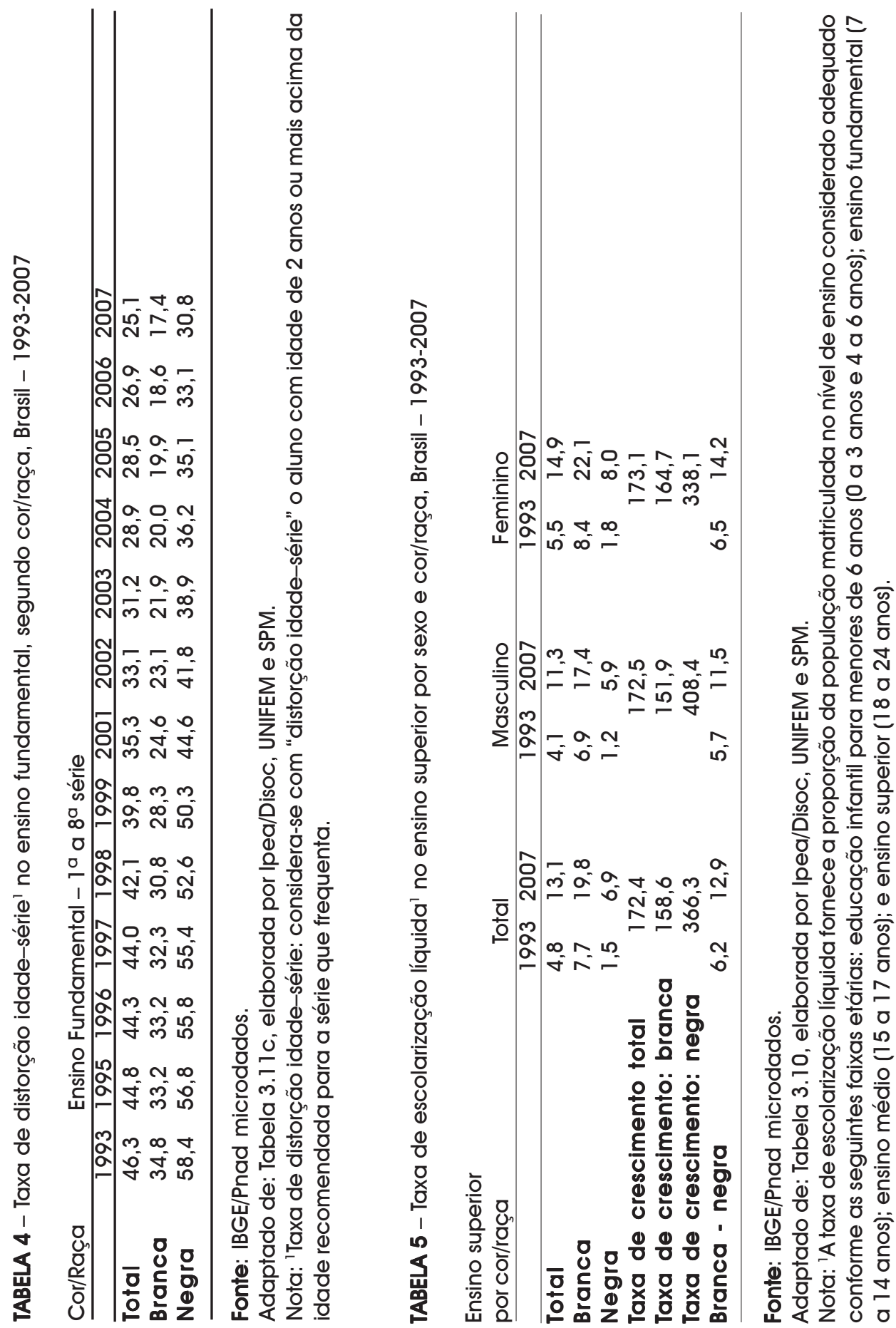


No ensino médio, a distorção idade-série é ainda mais elevada do que a identificada no ensino fundamental, sendo importante, para a compreensão desse fenômeno, além das variáveis racial e institucional, recorrer-se aos estudos sobre juventude. Paralelamente às experiências escolares, os jovens vivenciam espaços bastante heterogêneos de socialização - a rua, a família, a igreja, os grupos culturais, os grupos de amigos. Em meio ao surgimento de indagações e descobertas sobre as mais diversas experiências - tais como sexualidade, drogas, violência, desemprego e emprego, vestibular -, a escola vai perdendo o seu lugar de exclusividade na vida dos/as jovens. Assim, o distanciamento entre a cultura escolar e a cultura juvenil gera tensões que, por vezes, resultam na repetência, no abandono, na evasão e até na violência na escola.

\section{O ensino superior}

A importância da articulação de diferentes aspectos e categorias sociais para a compreensão das desigualdades educacionais se torna mais evidente na análise da situação do ensino superior. Apesar de os dados compilados no Retrato das desigualdades de gênero e raça referendarem o que já havia sido apontado por outros estudos, ou seja, a reversão do hiato de gênero na educação - com as mulheres passando a atingir maiores índices de escolarização ${ }^{14}$-, essa situação não é tão "confortável" no caso das mulheres negras no ensino superior.

Nos últimos anos, paralelamente à expansão de vagas no ensino superior e à implementação de ações afirmativas de acesso em algumas universidades, houve uma redução na desigualdade de acesso de brancos e negros à universidade. Enquanto a presença de estudantes negros de 18 a 24 anos no ensino superior cresceu em torno de $366 \%$, o aumento de estudantes brancos foi de aproximadamente $158 \%,{ }^{15}$ conforme se pode ver na Tabela 5. Isso fez com que a razão de representação de brancos e negros no ensino superior - ou seja, a quantidade de vezes que a população branca é maior do que a negra $^{16}$ - baixasse de aproximadamente 5 em 1993 para 3 em 2007.

Contudo, esse crescimento da presença da população negra no ensino superior é marcado por uma novidade em relação aos dados dos outros indicadores educacionais constantes no Retrato das desigualdades de gênero e raça: a melhor situação dos homens diante das mulheres em um determinado grupo racial, no caso o negro. Diferentemente do que acontece no grupo branco, o grupo negro apresenta as maiores taxas de crescimento do acesso ao ensino superior para os homens, tendo sua participação ampliada em $408 \%$ entre 1993 e 2007, enquanto que, no mesmo período, as mulheres negras tiveram um aumento de $338 \%$.

Isso indica a existência de mecanismos sexistas na passagem do ensino médio para o ensino superior que acometem marcadamente as mulheres negras, ${ }^{17}$ uma vez que elas não conseguem manter sobre os jovens negros o mesmo padrão de vantagem

\footnotetext{
${ }^{14}$ Segundo Kaisô Iwakami BELTRÃO e José Eustáquio Diniz ALVES (2009), essa inversão se iniciou na segunda metade do século XX, em função da pressão exercida pelo movimento feminista no Brasil e também das políticas públicas adotadas a partir da Revolução de 1930.

${ }^{15}$ A taxa de crescimento foi obtida da seguinte maneira: [(proporção em T1/proporção em TO) -1] x 100.

${ }^{16} \mathrm{~A}$ razão de representação de brancos e negros foi obtida pela divisão da porcentagem de brancos no ensino superior pela porcentagem de negros, num dado ano.

${ }^{17}$ As especificidades da luta da mulher negra nem sempre estiveram representadas nos movimentos feministas e nos movimentos negros. O reconhecimento das diferenças intragênero e intrarracial foi pautado pelas mulheres negras à medida que não se viam representadas nas demandas e ações empreendidas por esses movimentos sociais (Sueli CARNEIRO, 2003).
} 
alcançado nos outros indicadores do ensino básico. A manutenção dessa tendência de crescimento desigual no acesso ao ensino superior pode, no limite, provocar uma inversão na representação percentual de homens e mulheres negras nos próximos anos. ${ }^{18}$

Em relação à população negra, a ampliação de sua presença no ensino superior quando comparada com a da população branca no período considerado - e a consequente redução da desigualdade racial nesse segmento educacional - deve ser tomada com cautela.

Primeiro porque a diferença na representação das duas populações no ensino superior ainda é grande, com uma proporção de escolarização líquida em 2007 de 19,8\% para a população branca de 18 a 24 anos ante apenas 6,9\% para os negros da mesma idade (ver Tabela 5). Assim, mesmo com a diminuição da razão de representação de brancos e negros de 5 para 3 no período de 1993 a 2007, a diferença na proporção de membros dos dois grupos atendendo ao ensino superior aumentou de $6,2 \%$ para $12,9 \%$.

Em segundo lugar, porque a maior taxa de crescimento do acesso ao ensino superior da população negra não significa necessariamente que entre 1993 e 2007 tenha ocorrido uma grande transformação da sociedade brasileira em geral, e da escola em particular, no sentido do enfrentamento do preconceito e da discriminação raciais, que reduzem as chances de os jovens negros atingirem e concluírem o ensino superior. Mais adequada parece a suposição da centralidade de duas mudanças institucionais ocorridas nesse período: a ampliação de vagas no ensino superior e a instituição de programas de ação afirmativa em várias universidades brasileiras.

Ações afirmativas são benefícios temporários concedidos a grupos sociais discriminados com o intuito de promover a igualdade de oportunidade em diferentes dimensões da vida social, em especial na educação e no trabalho. Segundo Joaquim Barbosa Gomes, ${ }^{19}$ além de garantir a igualdade de oportunidades, as ações afirmativas têm como objetivo induzir a sociedade a transformações culturais que permitam que o preconceito racial seja desconstruído das mentes dos indivíduos e eliminado da estrutura das instituições.

Contudo, as ações afirmativas, por si só, não são suficientes para romper com as desigualdades raciais existentes no país. Devido à configuração da estrutura social brasileira, é necessário que essas políticas sejam implementadas em articulação com as políticas universais, especialmente no caso da educação. Ademais, em sociedades permeadas pelo racismo e por outras discriminações, é necessário haver uma articulação de políticas que visem não só à promoção da igualdade racial, mas também ao combate ao preconceito e à discriminação, inclusive por meio de um aparato repressivo-punitivo, conforme concordam Luciana Jaccoud e Mário Theodoro ${ }^{20}$ e Flávia Piovesan. ${ }^{21}$

\section{Considerações finais}

A análise dos dados compilados na $3^{a}$ edição do Retrato das desigualdades de gênero e raça mostrou que, a despeito do recuo apresentado no período compreendido

\footnotetext{
${ }^{18}$ Vale destacar que o problema do retorno desigual aos esforços desenvolvidos por homens e mulheres, que no caso do acesso ao ensino superior tem sido um problema específico para a mulher negra, expande-se para toda a população feminina brasileira quando se trata da relação entre educação e mercado de trabalho. As conquistas das mulheres na área da educação não têm se revertido em ascensão profissional semelhante à obtida pelos homens, seja em termos de melhores cargos ou salários. No mundo do trabalho, em iguais condições de escolaridade, as mulheres continuam recebendo salários mais baixos.

19 Joaquim Benedito Barbosa GOMES, 2005.

${ }^{20}$ Luciana de Barros JACCOUD e Mário THEODORO, 2005.

${ }^{21}$ Flávia PIOVESAN, 2005.
} 
entre meados dos anos 1990 e meados da primeira década dos anos 2000, as desigualdades raciais na educação ainda persistem e não dão mostras que cessarão se políticas públicas específicas não forem implementadas com esse objetivo.

Na educação básica, o processo de universalização do acesso à escola não foi suficiente para a erradicação das desigualdades raciais. Entre o começo da década passada e o final desta, houve, de fato, uma acentuada queda na desigualdade de acesso ao sistema educacional por crianças brancas e negras, o que, todavia, não foi suficiente para igualar a média de anos de estudo das crianças de 7 a 14 anos. Pior ainda, desde 2002 essa diferença tem se mantido aproximadamente constante.

A existência desse resíduo de desigualdade entre brancos e negros no segmento de ensino cujos indicadores apresentaram os maiores progressos no período em questão é um indício de que as distintas experiências vivenciadas por crianças brancas e negras no interior do sistema educacional têm efeito direto sobre sua permanência, progressão e desempenho escolar. Dentre as situações e os processos sociais que condicionam essas distintas experiências, destacam-se a prática de adjetivação desumanizadora das crianças negras, a omissão de professores diante das situações de discriminação sofridas por crianças negras, o estímulo e o tratamento mais afetivo legado à criança branca, além da invisibilidade histórica e cultural da população negra nos materiais didáticos.

A melhor compreensão desses - e de outros - mecanismos de reprodução das desigualdades raciais na educação possibilita a construção de respostas públicas mais efetivas. Esse é o caso, por exemplo, da Lei $n^{\circ} 10.639 / 2003$ (e das suas alterações pela Lei $n^{\circ} 11.645 / 2008$ ), que estabelece a obrigatoriedade do ensino da história e da cultura da África e das populações negras no Brasil. O currículo escolar durante muito tempo relegou à população negra apenas a condição de subalterna no processo escravista, sendo o lugar de escravo passivo o único que lhe cabia na história. Mas com a implantação da Lei $\mathrm{n}^{\circ} 11$. 645/2008 abre-se a possibilidade de mudanças nas abordagens sobre as contribuições dos povos africanos - e indígenas - para a constituição da sociedade brasileira.

Outra importante ação afirmativa para a transformação do quadro de desigualdades raciais no país são os programas de reserva de vagas para a população negra no ensino superior. Isso porque, a despeito do aumento da presença de negros nas universidades brasileiras nos últimos anos, ainda é enorme a diferença de representação de brancos e negros nesse segmento de ensino. Além do mais, essa ampliação do acesso da população negra ao ensino superior ocorreu paralelamente à ampliação de vagas nesse segmento de ensino e à própria introdução de programas de reserva de vagas em algumas universidades, o que sugere que esse avanço foi causado primordialmente por mudanças institucionais pontuais, não por mudanças no imaginário social nacional com vistas à construção de uma sociedade na qual brancos e negros sejam tratados da mesma forma e, por conseguinte, compitam em condição de igualdade.

Essa desigualdade de tratamento - que gera uma condição de desigualdade de oportunidade - é ainda mais grave em relação ao acesso das mulheres negras ao ensino superior. A taxa de crescimento do acesso dessas mulheres é inferior à taxa apurada para homens do mesmo grupo racial, e, se mantida essa tendência, pode haver no futuro a inversão da representação de homens e mulheres negras no ensino superior. Como hipóteses para essa taxa de crescimento desigual, destacam-se as formas de incidência do racismo e do sexismo sobre as trajetórias familiares, educacionais e profissionais das mulheres negras, que dificultam seu acesso a melhores condições e oportunidades de vida. Para a compreensão desse surpreendente fenômeno, faz-se necessária a realização de estudos que aprofundem essa discussão. 
Diante do exposto nestas poucas páginas, estas últimas linhas não poderiam ser usadas senão para apontar a necessidade da articulação de diferentes ações públicas para a superação das desigualdades raciais na educação. Nesse processo, é basilar a melhoria das escolas, principalmente as públicas, pois é nelas que está a grande maioria das crianças e dos jovens negros. Essa melhoria, entretanto, deve transcender à tão debatida e almejada qualidade de ensino; ela deve ser também uma melhoria do ambiente escolar, que o transforme em um espaço no qual a população negra sinta seus elementos históricos e culturais respeitados e valorizados. A reserva de vagas para negros no ensino superior, por sua vez, surge como uma perspectiva para a juventude negra escolarizada, estratégica para garantir o acesso da população negra a espaços de poder e, com isso, introduzir nesses espaços um novo referencial sobre os problemas e desafios do país.

\section{Referências bibliográficas}

BELTRÃO, Kaisô Iwakami; ALVES, José Eustáquio Diniz. "A reversão do hiato de gênero na educação brasileira no século XX". Cadernos de Pesquisa, São Paulo, v. 39, n. 136, p. 125-156, jan./abr. 2009.

BONAMINO, Alicia Maria Catalano de; FRANCO, Francisco Creso Junqueira; ALVES, Fátima. "The Color of Educational Inequalities." In: RESEARCH FOR RESULTS IN EDUCATION: A GLOBAL CONFERENCE ON EDUCATION RESEARCH IN DEVELOPING COUNTRIES, 2005, Praga. Disponível em: http://www.preal.org/FIE/pdf/lopbc/Bonamino.pdf. Acesso em: 10 dez. 2005.

CARNEIRO, Sueli. "Mulheres em movimento". Estudos Avançados, São Paulo, v. 17, n. 49, p. 117-132, dez. 2003.

CAVALLEIRO, Eliane dos Santos. "Discriminação racial e pluralismo em escolas públicas da cidade de São Paulo". In: SECRETARIA DE EDUCAÇÃO CONTINUADA, ALFABETIZAÇÃO E DIVERSIDADE. EDUCAÇÃO ANTI-RACISTA. Caminhos abertos pela Lei Federal n. 10.639/ 03. Brasília: MEC; Secad, 2005. p. 65-104.

GOMES, Joaquim Benedito Barbosa. "A recepção do instituto da ação afirmativa pelo Direito Constitucional brasileiro". In: SANTOS, Sales Augusto dos (Org.). Ações afirmativas e combate ao racismo nas Américas. Brasília: MEC; Secad, 2005. p. 45-80.

GOMES, Nilma Lino. "Educação, raça e gênero: relações imersas na alteridade". Cadernos Pagu: raça e gênero, Campinas: Unicamp, v. 6-7, p. 67-82, 1996.

GUIMARÃES, Antônio Sérgio Alfredo. "Como trabalhar com 'raça' em sociologia". Educação e Pesquisa, São Paulo, v. 29, n. 1, p. 93-107, 2003.

. "Preconceito de cor e racismo no Brasil". Revista de Antropologia, São Paulo, v. 4, n. 1, p. 9-43, 2004.

HASENBALG, Carlos; SILVA, Nelson do Valle. "Família, cor e acesso à escola no Brasil". In: HASENBALG, Carlos; SILVA, Nelson do Valle; LIMA, Márcia. Cor e estratificação social. Rio de Janeiro: Contra Capa, 1999. p. 126-147.

HENRIQUES, Ricardo. Desigualdade racial no Brasil: evolução das condições de vida na década de 90. Brasília: Ipea, 2001. Texto para discussão n. 807.

JACCOUD, Luciana de Barros; BEGHIN, Nathalie. Desigualdades raciais no Brasil: um balanço da intervenção governamental. Brasília: Ipea, 2002.

JACCOUD, Luciana de Barros; THEODORO, Mário. "Raça e educação: os limites das políticas universalistas". In: SANTOS, Sales Augusto dos (Org.). Ações afirmativas e combate ao racismo nas Américas. Brasília: MEC; Secad, 2005. p. 103-120.

MUNANGA, Kabengele. "Uma abordagem conceitual das noções de raça, racismo, identidade e etnia". In: BRANDÃO, André Augusto (Org.). Programa de Educação sobre o negro na sociedade brasileira. Niterói: Universidade Federal Fluminense, 2004. p. 15-34. 
PINHEIRO, Luana et al. Retrato das desigualdades de gênero e de raça. 3. ed. Brasília: Ipea, 2008.

PIOVESAN, Flávia. "Ações afirmativas sob a perspectiva dos direitos humanos". In: SANTOS, Sales Augusto dos (Org.). Ações afirmativas e combate ao racismo nas Américas. Brasília: MEC; Secad, 2005. p. 33-44.

SILVA, Nelson do Valle; HASENBALG, Carlos. "Tendências da desigualdade educacional no Brasil”. Dados, Rio de Janeiro, v. 43, n. 3, p. 423-445, 2000.

"Recursos familiares e transições educacionais". Cadernos de Saúde Pública, Rio de Janeiro, v. 18, p. 67-76, 2002.

SOARES, José Francisco; ALVES, Maria Teresa Gonzaga. "Desigualdades raciais no sistema brasileiro de educação básica". Educação e Pesquisa, São Paulo, v. 29, n. 1, p. 147 165, 2003.

SOUZA, Andréia Lisboa de. "A representação da personagem feminina negra na literatura infanto-juvenil brasileira". In: SECRETARIA DE EDUCAÇÃO CONTINUADA, ALFABETIZAÇÃO E DIVERSIDADE. Educação anti-racista: caminhos abertos pela Lei Federal n. 10.639/03. Brasilia: MEC; Secad, 2005. p. 185-204.

\begin{abstract}
Notes for the Interpretation of Racial Inequalities in Education
Abstract: This article discusses the educational data compiled in the 3rd Edition of the Gender and Race Inequalities Portrait, emphasizing the importance of understanding how the different situations and social processes experienced by white and black students affect their permanence, progression and performance in school. As main findings, we highlight: the decrease of the historical educational gap between whites and blacks aged over 15, the stagnation of the educational gap between white and black children from 7 to 14 years of age, as well as the slower rate of growth to access university by black women in comparison to that of black men. Finally, we argue in favor of integrating different kinds of policies to overcome the remaining racial inequalities in education.
\end{abstract}

Key Words: Racial Inequalities; Prejudice and Discrimination; Affirmative Actions; Public Policy. 